\title{
Levels of vaccination coverage among HIV-exposed children in China: a retrospective study
}

\author{
Rui Shen ${ }^{1}$, Ai-Ling Wang ${ }^{1 *}$, Xiao-Ping Pan ${ }^{1}$, Ya-Ping Qiao' ${ }^{1}$ Qian Wang ${ }^{1}$, Xiao-Yan Wang ${ }^{1}$, Shui-Ling Qu² \\ and Tong Zhang ${ }^{3^{*}}$ (D)
}

\begin{abstract}
Background: Vaccination is crucial for human immunodeficiency virus (HIV)-exposed children because of their increased risk of morbidity and mortality from various vaccine-preventable diseases. However, studies have shown that they are at high risk of incomplete vaccination. Although China has developed prevention of mother-to-child transmission (PMTCT) of HIV programs substantially over the past decades, few studies have investigated the immunization levels of Chinese HIV-exposed children. Therefore, we aimed to evaluate vaccination coverage and its associated factors among HIV-exposed children in China during 2016-2018.
\end{abstract}

Methods: We conducted a retrospective cohort review of all cases of Chinese HIV-exposed children born between July 1, 2016 and June 30, 2018 recorded in the Chinese information system on PMTCT. The vaccination coverage indicators refer to the percentage of children who received recommended basic vaccines, including Bacillus Calmette-Guérin (BCG), hepatitis B (HepB), polio, measles-containing vaccine (MCV), and diphtheria-tetanus-pertussiscontaining (DTP) vaccine. Univariate and multivariate logistic regression analyses expressed as crude odds ratios (cORs) and adjusted odds ratios (aORs), each with 95\% confidence intervals ( $95 \% \mathrm{Cl}$ ), were performed to compare the proportional differences of factors associated with vaccine coverage.

Results: Among the enrolled 10033 children, the vaccination rate was $54.1 \%$ for BCG, 84.5\% for complete HepB vaccination, $54.5 \%$ for complete polio vaccination, $51.3 \%$ for MCV, and $59.5 \%$ for complete DTP vaccination. Children with perinatally acquired HIV (PHIV) were 2.46-3.82 times less likely to be vaccinated than HIV-exposed uninfected children. Multivariate logistic regression indicated that children of Han ethnicity $(a O R=1.33-2.04)$, children with early infant diagnosis (EID) of HIV ( $\mathrm{aOR}=1.86-3.17)$, and children whose mothers had better education (college or above, $\mathrm{a} O R=1.63-2.51)$ had higher odds of being vaccinated. Most of the deceased children ( $\mathrm{a} O R=4.28-21.55)$ missed vaccination, and PHIV ( $a O R=2.46-3.82)$ significantly affected immunization.

Conclusions: Chinese HIV-exposed children had low vaccination coverage, which is a serious health challenge that needs to be addressed thoroughly. Interventions should be developed with a focus on minority HIV-exposed children

\footnotetext{
*Correspondence: ailing@chinawch.org.cn; zt@chinawch.org.cn

${ }^{1}$ National Center for Women and Children's Health, Chinese Center

for Disease Control and Prevention, No. 12 Dahuisi Road, Haidian District, Beijing 100081, China

${ }^{3}$ Capital Institute of Pediatrics, No. 2 Yabao Road, Chaoyang District, Beijing 100020, China

Full list of author information is available at the end of the article
} permits use, sharing, adaptation, distribution and reproduction in any medium or format, as long as you give appropriate credit to the original author(s) and the source, provide a link to the Creative Commons licence, and indicate if changes were made. The images or other third party material in this article are included in the article's Creative Commons licence, unless indicated otherwise in a credit line to the material. If material is not included in the article's Creative Commons licence and your intended use is not permitted by statutory regulation or exceeds the permitted use, you will need to obtain permission directly from the copyright holder. To view a copy of this licence, visit http://creativecommons.org/licenses/by/4.0/. The Creative Commons Public Domain Dedication waiver (http://creativeco mmons.org/publicdomain/zero/1.0/) applies to the data made available in this article, unless otherwise stated in a credit line to the data. 
whose mothers do not have formal education. Particularly, more attention should be paid to EID to increase access to immunization.

Keywords: HIV, Children, Coverage, Vaccination, China

\section{Background}

Immunization has been identified as one of the most cost-effective interventions in global health. The World Health Organization (WHO) monitors vaccine coverage as a key indicator of children's health services [1]. However, studies have shown that children born to human immunodeficiency virus (HIV)-infected women have $30-70 \%$ chance of being incompletely immunized [2-4]. Compared to infants of uninfected mothers, these children are reported to have a markedly higher early life burden of infectious diseases for their immunological disorders $[5,6]$. Low vaccination coverage may increase the morbidity and mortality risk from vaccine-preventable diseases among such children [7-9].

With the effectiveness of prevention of mother-to-child transmission (PMTCT) interventions well established, China has reduced the mother-to-child transmission rate of HIV to $4.9 \%$ in 2017 [10]. Most children of Chinese HIV-infected mothers are not infected with HIV, but the mortality rate among those aged $0-18$ months is as high as $4.9-7.8 \%$ [11-13], which is significantly higher than the Chinese national infant mortality rate of $0.61 \%$ [14]. Infectious diseases remain a major cause of death among HIV-exposed children [12, 15, 16].

Previous studies indicated that one reason for increased mortality among children born to HIV-positive mothers might be that those children are less likely to receive routine childhood vaccinations $[4,17]$. However, few studies have reported immunization levels in HIV-exposed Chinese children. Given the importance of vaccination for HIV-exposed children and the data from other countries, suggesting that they are at a higher risk of under-vaccination, we evaluated the vaccination rates and factors affecting the vaccination status of HIV-exposed children in China.

\section{Methods}

\section{Study design and setting}

This was a retrospective cohort study using data from the Chinese information system for PMTCT. This longitudinal, population-based health and vital event registration system monitors HIV-exposed children and their mothers. It is implemented through mandatory case reporting by health facilities in all 31 provincial-level administrative divisions of China. For each child, data collected include maternal demographic characteristics (e.g., maternal age, occupation, education, ethnicity, marital status, and parity), child's characteristics (e.g., sex, birth weight, and HIV status), and clinically standardized follow-up information (HIV laboratory assessment, vaccination history, HIV-related diseases and symptoms, and survival status). These data are prospectively collected both at birth and at $1,3,6,9,12,15$, and 18 months of age $[13,18,19]$.

\section{Study population}

The target population in the study was perinatally HIVexposed children, with the following criteria: (1) born to HIV-infected women, (2) live birth, and (3) born between July 1, 2016 and June 30, 2018. Children who were lost to follow-up were excluded. All the appropriate cases in the PMTCT information system were included in this study.

\section{Data source and variables}

Variables and data related to vaccination status were extracted from PMTCT information system-belongs to China CDC, which is not open for the public-using a standardized data abstraction form. The study variables included maternal age, ethnicity, marital status, parity, education, and occupation; and the child's gender, birth weight, HIV status, HIV-related diseases (pathological jaundice, upper respiratory tract infection, pathological diarrhea, pneumonia, anemia, rickets, or severe malnutrition), HIV-related symptoms (intermittent or persistent fever, persistent cough, rash, systemic lymphadenopathy, Candida albicans infection, or hepatosplenomegaly), and survival status (alive or dead). HIV infection was diagnosed according to reactive HIV tests on two different occasions: positive virological tests under 18 months of age or positive antibody tests up to 18 months. Early infant diagnosis (EID) is used to diagnose babies born to HIV-infected mothers as recommended by the WHO. In our study, HIV-exposed children undergo EID at 42 days and 3 months of age to confirm HIV status by HIV virological tests. According to the WHO [20] and the Chinese National Immunization Programme schedule [21], vaccination coverage indicators refer to the percentage of children who received recommended basic vaccines, including one dose of Bacillus Calmette-Guérin (BCG) vaccine, three doses of hepatitis $B$ (HepB) vaccine, three doses of polio vaccine (live oral poliovirus vaccine or inactivated poliovirus vaccine), one dose of measles-containing vaccine $(\mathrm{MCV})$, and three doses of diphtheriatetanus-pertussis-containing (DTP) vaccine. Children were classified as up to date (UTD) if they had received 
the recommended dose of vaccines before 12 months of age.

\section{Immunization schedule}

According to the Chinese immunization guidelines [21] (Table 1), children born to HIV-infected mothers should not be vaccinated with oral poliomyelitis vaccine (OPV) and BCG; these vaccinations should be postponed until the children are confirmed as not infected with HIV. Children with HIV-related or immunosuppressive symptoms should not be vaccinated with MCV. HIV-exposed uninfected (HEU) infants are recommended to have immunization as is routinely administered to other children, including one dose of BCG after birth, three doses of HepB vaccine (at birth, 1 month, and 6 months of age), three doses of polio vaccine (at 2, 3, and 4 months of age), three doses of DTP vaccine (at 3, 4, and 5 months of age), and one dose of MCV (at 8 months).

\section{Statistical analysis}

Statistical analysis was performed using the statistical software SPSS 25.0 (International Business Machines Corporation, Armonk, USA). Immunization status was presented as numbers and percentages. Proportions were compared by Chi-square tests. Univariate and multivariate logistic regression analyses were performed to compare the proportional differences in factors associated with vaccination coverage. Univariate logistic regression was used for categorical variables to explore potential factors affecting immunization. Multivariate logistic regression using the forward likelihood ratio method was utilized to analyze factors associated with non-uptake of vaccines among the studied population. Crude odds ratio $(\mathrm{cOR})$ and adjusted odds ratio $(\mathrm{a} O R)$ were calculated with logistic regression. Significance tests were two-tailed, and $P$ values $<0.05$ were considered statistically significant.

\section{Results}

\section{Overall characteristics of the population}

We included 10033 live-born HIV-exposed children born from July 1, 2016 to June 30, 2018, excluding 119 children lost to follow-up. The characteristics of the enrolled children and their mothers are reported in Table 2. There were 306 children with perinatally acquired HIV (PHIV), 341 with unknown HIV status, and 9386 HEU children among the 10033 enrolled children. We found that 49.5\% of the children were of Han ethnicity, $89.6 \%$ had EID to determine HIV status, $11.6 \%$ had at least one HIV-related symptom, and $17.0 \%$ had at least one HIV-related disease during the 18 months of follow-up. In all, $3.0 \%$ of the children died during the 18 months of follow-up. Most of the HIV-infected mothers lived with a spouse (92.7\%), were aged $20-34$ years $(77.9 \%)$, graduated from middle school (48.8\%), farmed at home (56.1\%), and had given birth to $2-3$ babies (55.9\%).

\section{Vaccination status}

Vaccination coverage

For the 10033 children included in the analysis, the BCG vaccination rate was $54.1 \%$, excluding 150 cases with unknown BCG vaccination status. The vaccination rates for three injections of HepB were respectively 97.1, 89.9 , and $84.5 \%$, excluding 131 cases of missing НерB vaccination data. The first dose of the polio vaccine was received by $63.5 \%$ of the children, the second by $58.7 \%$, and the third by $54.5 \%$, excluding 206 cases of insufficient reporting. MCV rate was 51.3\%, excluding 211 cases of unknown vaccination status; DTP vaccination rate was $66.3 \%$ for the first dose, and the complete vaccination rate for three injections was 59.5\%, excluding 212 cases of insufficient data. Compared with HEU children, children with PHIV were less likely to be vaccinated with BCG (28.9 vs 55.7\%), HepB1 (90.5 vs $98.0 \%$ ), Polio1 (33.0 vs

Table 1 Chinese immunization recommendations for HIV-exposed infants

\begin{tabular}{|c|c|c|c|c|c|}
\hline \multirow[t]{2}{*}{ Vaccines } & \multicolumn{2}{|l|}{ HIV-infected infants } & \multicolumn{2}{|l|}{ Unknown HIV status } & \multirow{2}{*}{$\begin{array}{l}\text { HIV- } \\
\text { uninfected } \\
\text { infants }\end{array}$} \\
\hline & $\begin{array}{l}\text { Have symptoms } \\
\text { or immunosuppression }\end{array}$ & $\begin{array}{l}\text { Asymptomatic and non- } \\
\text { immunosuppressive }\end{array}$ & $\begin{array}{l}\text { Have symptoms } \\
\text { or immunosuppression }\end{array}$ & Asymptomatic & \\
\hline $\mathrm{BCG}$ & $\times$ & $\times$ & Postponed & Postponed & $\sqrt{ }$ \\
\hline НерВ & $\sqrt{ }$ & $\sqrt{ }$ & $\sqrt{ }$ & $\sqrt{ }$ & $\sqrt{ }$ \\
\hline IPV & $\sqrt{ }$ & $\sqrt{ }$ & $\sqrt{ }$ & $\sqrt{ }$ & $\sqrt{ }$ \\
\hline OPV & $\times$ & $\times$ & $\times$ & $\times$ & $\sqrt{ }$ \\
\hline MCV & $\times$ & $\sqrt{ }$ & $\times$ & $\sqrt{ }$ & $\sqrt{ }$ \\
\hline DTP & $\sqrt{ }$ & $\sqrt{ }$ & $\sqrt{ }$ & $\sqrt{ }$ & $\sqrt{ }$ \\
\hline
\end{tabular}

$B C G$ Bacillus-Calmette-Guérin, DTP diphtheria, tetanus, and pertussis, HepB hepatitis $B, H I V$ human immunodeficiency virus, IPV inactivated poliovirus vaccine, MCV measles-containing vaccine, OPV oral poliovirus vaccine

$\sqrt{ }:$ Recommended

$x$ : Not recommended 
Table 2 Maternal and child characteristics in the study population

\begin{tabular}{|c|c|c|c|c|c|}
\hline \multirow[t]{3}{*}{ Variables } & \multirow{3}{*}{$\begin{array}{l}\text { Total } N=10033 \\
N(\%)\end{array}$} & \multicolumn{3}{|l|}{ HIV status } & \multirow[t]{3}{*}{$P$-value } \\
\hline & & \multirow{2}{*}{$\begin{array}{l}\text { HEU } \\
n(\%)\end{array}$} & \multirow{2}{*}{$\begin{array}{l}\text { PHIV } \\
n(\%)\end{array}$} & \multirow{2}{*}{$\begin{array}{l}\text { Unknown } \\
n(\%)\end{array}$} & \\
\hline & & & & & \\
\hline Sex & & & & & 0.028 \\
\hline Male & $5168(51.5)$ & $4864(51.8)$ & $136(44.4)$ & $168(49.3)$ & \\
\hline Female & $4865(48.5)$ & $4522(48.2)$ & $170(55.6)$ & $173(50.7)$ & \\
\hline Birth weight (g) & & & & & 0.030 \\
\hline$<2500$ & $1261(12.6)$ & $1161(12.4)$ & $38(12.4)$ & $62(18.2)$ & \\
\hline 2500-4000 & 8607 (85.8) & $8073(86.0)$ & $258(84.3)$ & $276(80.9)$ & \\
\hline$>4000$ & $165(1.6)$ & $152(1.6)$ & $10(3.3)$ & $3(0.9)$ & \\
\hline EID & & & & & $<0.001$ \\
\hline Yes & 8994 (89.6) & $8680(92.5)$ & $295(96.4)$ & $19(5.6)$ & \\
\hline No & $1039(10.4)$ & $706(7.5)$ & $11(3.6)$ & $322(94.4)$ & \\
\hline HIV-related diseases & & & & & $<0.001$ \\
\hline No & $8329(83.0)$ & 7995 (85.2) & $174(56.9)$ & $160(46.9)$ & \\
\hline Yes & $1704(17.0)$ & $1391(14.8)$ & $132(43.1)$ & $181(53.1)$ & \\
\hline HIV-related symptoms & & & & & $<0.001$ \\
\hline No & 8870 (88.4) & 8500 (90.6) & $199(65.0)$ & $171(50.1)$ & \\
\hline Yes & $1163(11.6)$ & $886(9.4)$ & $107(35.0)$ & $170(49.9)$ & \\
\hline Survival status & & & & & $<0.001$ \\
\hline Live & $9730(97.0)$ & $9285(98.9)$ & $235(76.8)$ & $210(61.6)$ & \\
\hline Dead & $303(3.0)$ & $101(1.1)$ & $71(23.2)$ & $131(38.4)$ & \\
\hline Maternal age (years) & & & & & 0.022 \\
\hline$<20$ & $345(3.5)$ & $314(3.3)$ & $10(3.3)$ & $21(6.2)$ & \\
\hline $20-34$ & 7819 (77.9) & $7329(78.1)$ & $227(74.2)$ & $263(77.1)$ & \\
\hline$\geq 35$ & $1869(18.6)$ & $1743(18.6)$ & $69(22.5)$ & $57(16.7)$ & \\
\hline Ethnicity & & & & & 0.006 \\
\hline Han & $4963(49.5)$ & $4676(49.8)$ & $125(40.8)$ & $162(47.5)$ & \\
\hline Minority & $5070(50.5)$ & $4710(50.2)$ & $181(59.2)$ & $179(52.5)$ & \\
\hline Marital status & & & & & 0.017 \\
\hline Single & $730(7.3)$ & $665(7.1)$ & $29(9.5)$ & $36(10.6)$ & \\
\hline Married/cohabitated & $9303(92.7)$ & $8721(92.9)$ & $277(90.5)$ & $305(89.4)$ & \\
\hline Education & & & & & $<0.001$ \\
\hline Primary or lower & $4255(42.4)$ & $3936(41.9)$ & $160(52.3)$ & $159(46.6)$ & \\
\hline Middle school & $4897(48.8)$ & $4617(49.2)$ & $128(41.8)$ & $152(44.6)$ & \\
\hline College or above & $700(7.0)$ & $674(7.2 \%)$ & $12(3.9)$ & $14(4.1)$ & \\
\hline Unknown & $181(1.8)$ & $159(1.7)$ & $6(2.0)$ & $16(4.7)$ & \\
\hline Occupation & & & & & 0.083 \\
\hline Farmer & $5628(56.1)$ & $5295(56.4)$ & $165(53.9)$ & $168(49.3)$ & \\
\hline Housewife/unemployed & $2678(26.7)$ & $2488(26.5)$ & $89(29.1)$ & $101(29.6)$ & \\
\hline Others & $1727(17.2)$ & $1603(17.1)$ & $52(17.0)$ & $72(21.1)$ & \\
\hline Parity & & & & & 0.086 \\
\hline 1 & $1981(19.8)$ & $1829(19.5)$ & $67(21.9)$ & $85(24.9)$ & \\
\hline $2-3$ & $5610(55.9)$ & $5259(56.0)$ & $165(53.9)$ & $186(54.6)$ & \\
\hline$>3$ & $2442(24.3)$ & $2298(24.5)$ & $74(24.2)$ & $70(20.5)$ & \\
\hline
\end{tabular}

EID early infant diagnosis, HEU HIV-exposed uninfected, HIV human immunodeficiency virus, $N$ number of children, $n$ : number of children with the characteristic, $P H I V$ perinatally acquired HIV, children perinatally infected with HIV from mothers

a Chi-square test 
65.7\%), MCV (19.7 vs 53.4\%), and DTP1 (37.6 vs $68.5 \%$ ). Children with PHIV were also less likely to have received the second and third doses of HepB, polio, and DTP vaccines than HEU children (Table 3).

\section{Vaccination up to date status}

HEU children were significantly $(P<0.05)$ more likely to be UTD for each vaccine by 12 months of age, and the probability of being UTD for HEU children was 3.00-4.65 times more than that of children with PHIV (Table 4). Differences in UTD status between PHIV and HEU groups were large: BCG (27.0 vs 52.6\%), HepB3 (50.8 vs $82.8 \%$ ), Polio3 (19.1 vs $51.3 \%$ ), MCV (17.1 vs $48.6 \%)$, and DTP3 (25.4 vs 55.5\%). Only 9.3\% of children with PHIV had received all five routine vaccines at 12 months of age, compared to $34.4 \%$ of HEU children (Table 5).

\section{Vaccination factors}

In univariate analysis, there were significant $(P<0.05)$ associations of child characteristics (survival status, HIV status, HIV-related symptoms, and EID) and maternal features (ethnicity, education, and occupation)

Table 3 Vaccination coverage of five basic vaccines in the study population

\begin{tabular}{|c|c|c|c|c|c|c|}
\hline \multirow[t]{2}{*}{ Vaccines } & \multirow[t]{2}{*}{ Total $N$} & \multirow{2}{*}{$\begin{array}{l}\text { Vaccinated children } \\
n(\%)\end{array}$} & \multicolumn{3}{|l|}{ HIV status } & \multirow[t]{2}{*}{$P$-value } \\
\hline & & & HEU $n(\%)$ & PHIV $n(\%)$ & Unknown $n(\%)$ & \\
\hline $\mathrm{BCG}$ & 9883 & $5346(54.1)$ & $5192(55.7)$ & 88 (28.9) & $66(25.3)$ & $<0.001$ \\
\hline HepB1 & 9902 & $9611(97.1)$ & $9141(98.0)$ & $276(90.5)$ & $194(72.1)$ & $<0.001$ \\
\hline HepB2 & 9902 & 8901 (89.9) & $8583(92.0)$ & $223(73.1)$ & $95(35.3)$ & $<0.001$ \\
\hline НерВ3 & 9902 & $8370(84.5)$ & $8149(87.4)$ & $163(53.4)$ & $58(21.6)$ & $<0.001$ \\
\hline Polio1 & 9827 & $6236(63.5)$ & $6092(65.7)$ & $100(33.0)$ & $44(17.5)$ & $<0.001$ \\
\hline Polio2 & 9827 & $5772(58.7)$ & $5657(61.0)$ & $78(25.7)$ & $37(14.7)$ & $<0.001$ \\
\hline Polio3 & 9827 & $5354(54.5)$ & $5253(56.6)$ & $67(22.1)$ & $34(13.5)$ & $<0.001$ \\
\hline MCV & 9822 & $5044(51.3)$ & $4951(53.4)$ & 60 (19.7) & $33(13.1)$ & $<0.001$ \\
\hline DTP1 & 9821 & $6514(66.3)$ & $6349(68.5)$ & $114(37.6)$ & $51(20.2)$ & $<0.001$ \\
\hline DTP2 & 9821 & $6210(63.2)$ & 6069 (65.5) & $100(33.0)$ & $41(16.3)$ & $<0.001$ \\
\hline DTP3 & 9821 & $5842(59.5)$ & $5714(61.7)$ & 89 (29.4) & $39(15.5)$ & $<0.001$ \\
\hline
\end{tabular}

BCG Bacillus-Calmette-Guérin, DTP diphtheria-tetanus-pertussis-containing, HEU HIV-exposed uninfected, HIV human immunodeficiency virus, HepB hepatitis B, MCV measles-containing vaccine, $N$ number of children, $n$ number of children with the characteristic, PHIV perinatally acquired HIV, children perinatally infected with HIV from mothers

a Chi-square test

Table 4 Vaccination up to date status in the study population

\begin{tabular}{|c|c|c|c|c|c|c|c|c|}
\hline \multirow[t]{3}{*}{ Vaccine } & \multirow[t]{3}{*}{ Total $N$} & \multirow[t]{3}{*}{ UTD n (\%) } & \multicolumn{2}{|l|}{ PHIV } & \multicolumn{2}{|l|}{ HEU } & \multicolumn{2}{|c|}{ Unknown } \\
\hline & & & $n(\%)$ & OR $(95 \% C l)$ & $n(\%)$ & OR $(95 \% C l)$ & $n(\%)$ & OR $(95 \% C l)$ \\
\hline & & & & $P$-value ${ }^{a}$ & & $P$-value ${ }^{a}$ & & $P$-value ${ }^{a}$ \\
\hline$B C G$ & 9883 & $5041(51.0)$ & $82(27.0)$ & $\begin{array}{l}1.00 \\
-\end{array}$ & $4900(52.6)$ & $\begin{array}{l}3.00(2.32-3.88) \\
<0.001\end{array}$ & 59 (22.6) & $\begin{array}{l}0.79(0.54-1.16) \\
0.232\end{array}$ \\
\hline HepB3 & 9902 & $7928(80.1)$ & 155 (50.8) & $\begin{array}{l}1.00 \\
-\end{array}$ & 7720 (82.8) & $\begin{array}{l}4.65(3.69-5.85) \\
<0.001\end{array}$ & 53 (19.7) & $\begin{array}{l}0.24(0.16-0.35) \\
<0.001\end{array}$ \\
\hline Polio3 & 9827 & $4848(49.3)$ & 58 (19.1) & $\begin{array}{l}1.00 \\
-\end{array}$ & $4758(51.3)$ & $\begin{array}{l}4.45(3.33-5.94) \\
<0.001\end{array}$ & $32(12.7)$ & $\begin{array}{l}0.62(0.39-0.99) \\
0.044\end{array}$ \\
\hline MCV & 9822 & $4582(46.6)$ & $52(17.1)$ & $\begin{array}{l}1.00 \\
-\end{array}$ & 4504 (48.6) & $\begin{array}{l}4.58(3.39-6.20) \\
<0.001\end{array}$ & $26(10.3)$ & $\begin{array}{l}0.56(0.34-0.92) \\
0.023\end{array}$ \\
\hline DTP3 & 9821 & $5257(53.5)$ & $77(25.4)$ & $\begin{array}{l}1.00 \\
-\end{array}$ & $5144(55.5)$ & $\begin{array}{l}3.66(2.82-4.76) \\
<0.001\end{array}$ & $36(14.3)$ & $\begin{array}{l}0.49(0.32-0.76) \\
0.001\end{array}$ \\
\hline
\end{tabular}

BCG Bacillus-Calmette-Guérin, Cl confidence interval, DTP diphtheria-tetanus-pertussis-containing, HEU HIV-exposed uninfected, HIV human immunodeficiency virus, HepB hepatitis B, MCV measles-containing vaccine, $N$ number of children, $n$ number of children with the characteristic, OR odds ratio, $P H I V$ perinatally acquired HIV, children perinatally infected with HIV from mothers, UTD up to date, children were classified as up to date if they had received the recommended dose of vaccines before 12 months of age. - means not applicable

a Univariate logistic regression 
Table 5 Number of vaccines up to date in the study population

\begin{tabular}{|c|c|c|c|c|c|c|c|}
\hline \multirow[t]{2}{*}{ Number of vaccines UTD } & \multirow[t]{2}{*}{ Total $N=10,033 n(\%)$} & \multicolumn{2}{|l|}{ PHIV } & \multicolumn{2}{|l|}{ HEU } & \multicolumn{2}{|l|}{ Unknown } \\
\hline & & $n(\%)$ & $\begin{array}{l}\text { OR }(95 \% C l) \\
P \text {-value }^{\mathrm{a}}\end{array}$ & $n(\%)$ & $\begin{array}{l}\text { OR }(95 \% C l) \\
P \text {-value }\end{array}$ & $n(\%)$ & $\begin{array}{l}\text { OR }(95 \% C l) \\
P \text {-value }\end{array}$ \\
\hline None UTD ${ }^{b}$ & $1462(14.9)$ & $124(40.9)$ & 1.00 & $1164(12.6)$ & $\begin{array}{l}1.00 \\
-\end{array}$ & $174(70.2)$ & $\begin{array}{l}1.00 \\
-\end{array}$ \\
\hline 1-4 UTD & $5107(52.1)$ & $151(49.8)$ & 1.00 & $4904(53.0)$ & $\begin{array}{l}3.46(2.71-4.43) \\
<0.001\end{array}$ & $52(21.0)$ & $\begin{array}{l}0.25(0.17-0.36) \\
<0.001\end{array}$ \\
\hline All UTDC & $3230(33.0)$ & $28(9.3)$ & 1.00 & $3180(34.4)$ & $\begin{array}{l}12.10(7.99-18.33) \\
<0.001\end{array}$ & $22(8.9)$ & $\begin{array}{l}0.56(0.31-1.02) \\
0.06\end{array}$ \\
\hline Missing or insufficient data & 234 & 3 & - & 138 & - & 93 & - \\
\hline
\end{tabular}

Cl confidence interval, HEU HIV-exposed uninfected, $N$ number of children, $n$ number of children with the characteristic, OR odds ratio, PHIV perinatally acquired HIV, children perinatally infected with HIV from mothers, UTD up to date, children were classified as up to date if they had received the recommended dose of vaccines before 12 months of age; - means not applicable

a Univariate logistic regression;

b None UTD: None of the targeted vaccines was UTD at 12 months old;

c All vaccines UTD include: BCG, Hep B, MCV, DTP and Polio

with vaccination status (Table 6). Marital status and HIV-related diseases varied among those who received vaccines. Vaccine status had no statistical $(P>0.05)$ association with child's sex and birth weight, and maternal age and parity. HEU children were significantly $(P<0.05)$ more likely to be vaccinated than children with PHIV. In the multivariate analysis, five characteristics (maternal education, maternal ethnicity, child's HIV status, child survival status, and whether or not EID was done) remained independently associated with vaccination status after controlling covariates (Table 7). Most of the dead children missed vaccination $(\mathrm{aOR}=4.28-21.55)$. HIV status (HEU vs PHIV, aOR $=2.46-3.82$ ) and EID $(\mathrm{aOR}=1.86-3.17)$ played significantly crucial roles in vaccination, as did ethnicity (Han vs minority, $\mathrm{a} O R=1.33-2.04)$. For other variables, children of housewives/unemployed mothers had higher odds of being vaccinated than those of farmers for Polio3 $[\mathrm{a} O R=1.15$, 95\% confidence interval $(C I):$ 1.03-1.28], $\mathrm{MCV}$ $(\mathrm{a} O R=1.15,95 \% C I: 1.03-1.28)$, and DTP3 $(\mathrm{aOR}=1.39$, 95\% CI: 1.24-1.55).

Multivariate analysis showed that HIV-related symptoms were associated with BCG status $(\mathrm{aOR}=0.86$, 95\% CI: 0.75-0.99) and MCV status $(\mathrm{aOR}=0.84,95 \%$ CI: 0.72-0.97). However, co-linearity diagnostics indicated that HIV-related symptoms correlated with survival status (Pearson correlation $=0.287, P<0.05$ ). In the subgroup analysis, HIV-related symptoms showed no difference for BCG or MCV vaccination status in both dead children (BCG: $P=0$ 0.200, MCV: $P=1.000$ ) and living children (BCG: $P=0.066$, MCV: $P=0.129$ ). In contrast, survival status had a significant association with BCG or MCV vaccine status, with or without symptoms
$(P<0.05)$. Therefore, we excluded HIV-related symptoms from multivariate analysis.

\section{Discussion}

This study is the first to examine immunization coverage in a cohort of HIV-exposed Chinese children. Our study showed low vaccination coverage among children born to HIV-infected women in China. Compared with the WHO-reported Chinese immunization coverage among 1-year-olds (99-100\%) for the five examined vaccines [22], HIV-exposed children in this study had a significantly lower coverage level.

The administration of live attenuated vaccines (BCG and $\mathrm{MCV}$ ) was different in HIV-exposed children from routine practice. For children with PHIV, the WHO recommends that BCG vaccination should be delayed until the infants start antiretroviral therapy (ART) and remain immunologically stable (CD4\% > 25\%) [23] and that MCV should be routinely administered to potentially susceptible, asymptomatic HIV-infected children [24]. It is also recommended that routine childhood vaccines, whether live-attenuated or killed, should be administered to HEU children. Our study showed that only $52.6 \%$ of the HEU group had received the BCG vaccine by their first birthday, which is lower than the figure reported in Latin America and the Caribbean (HEU, 94.2\% at 12 months old) [25]. The MCV UTD rate was also lower than previously reported levels (HEU, $94.4 \%$ at 4 years old) [26]. Our study also shows that the subjects were under-vaccinated with inactivated vaccines, which should be administered as usual. One explanation for this may be that the HIV-related poor parental practices [27, 28] block the availability of immunization services for children. 


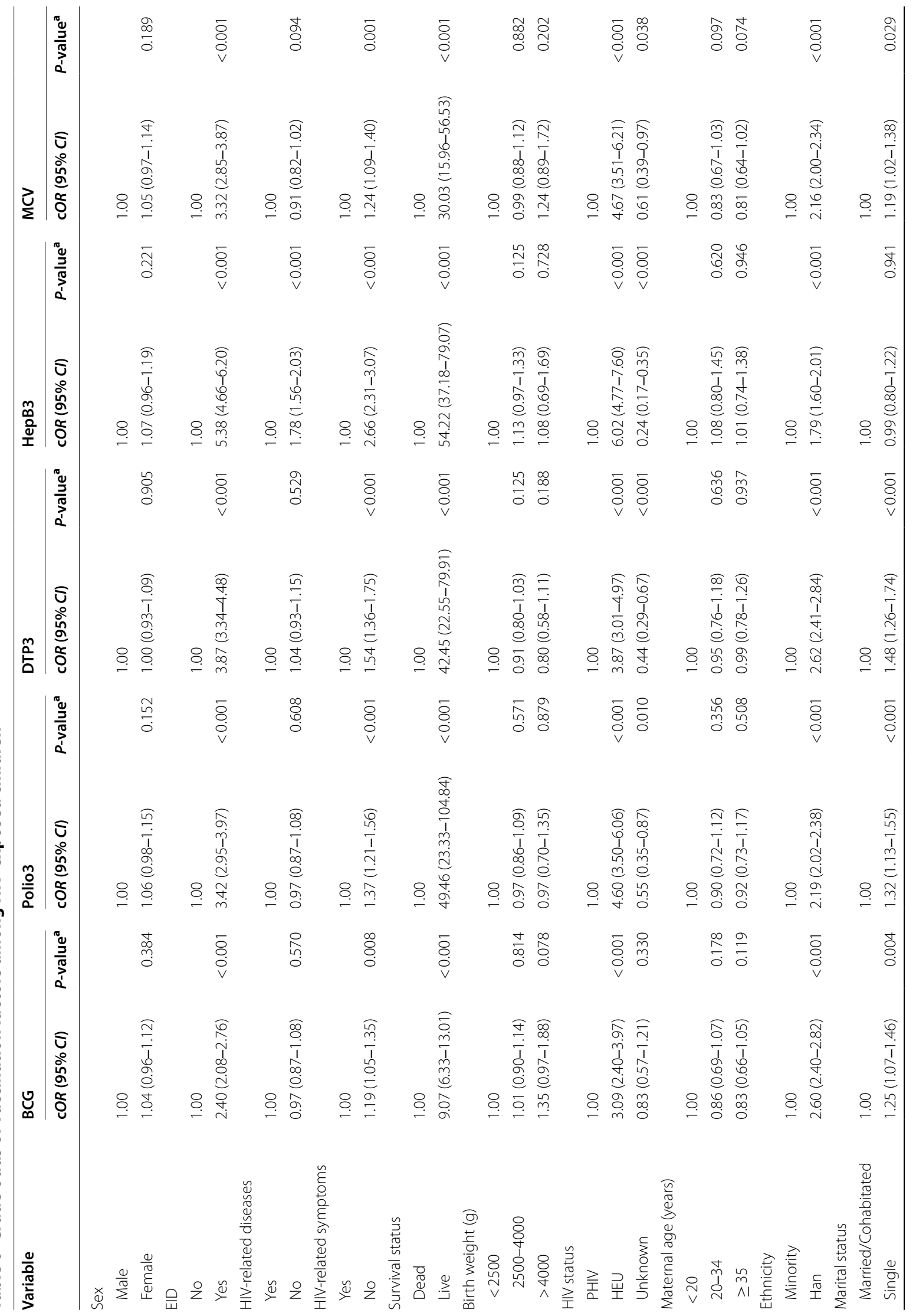




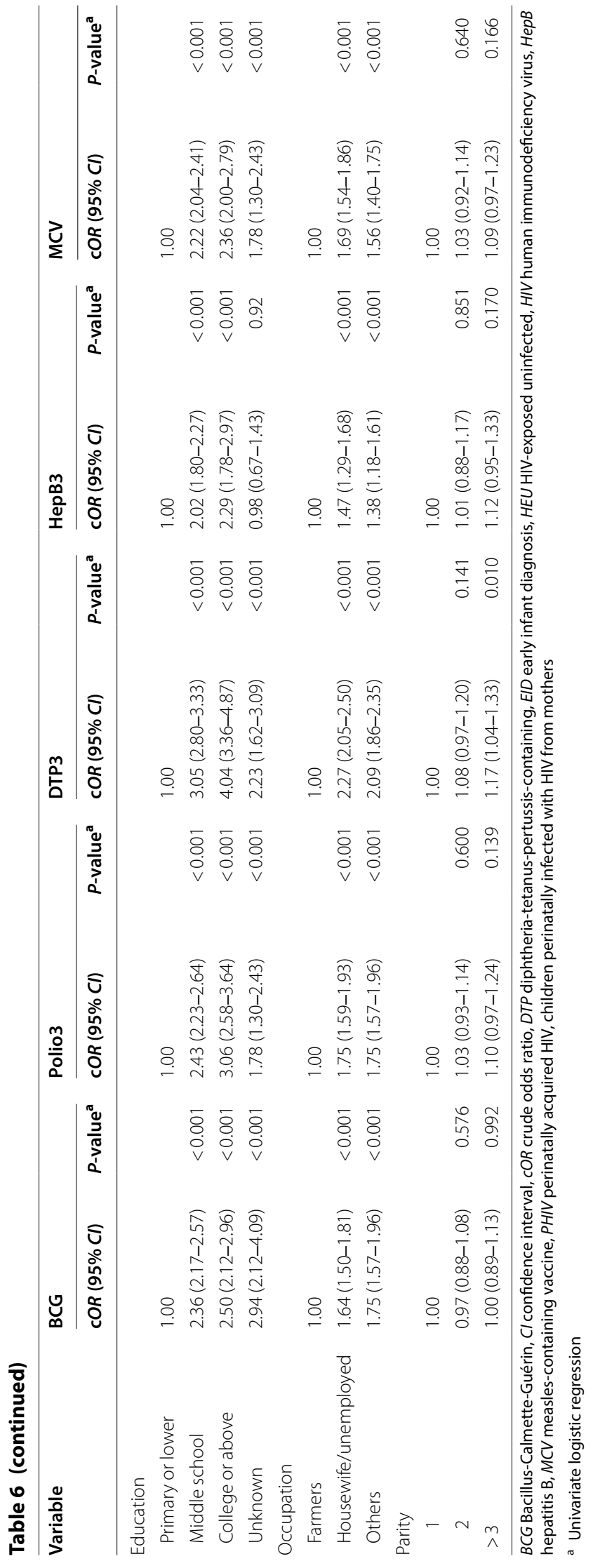




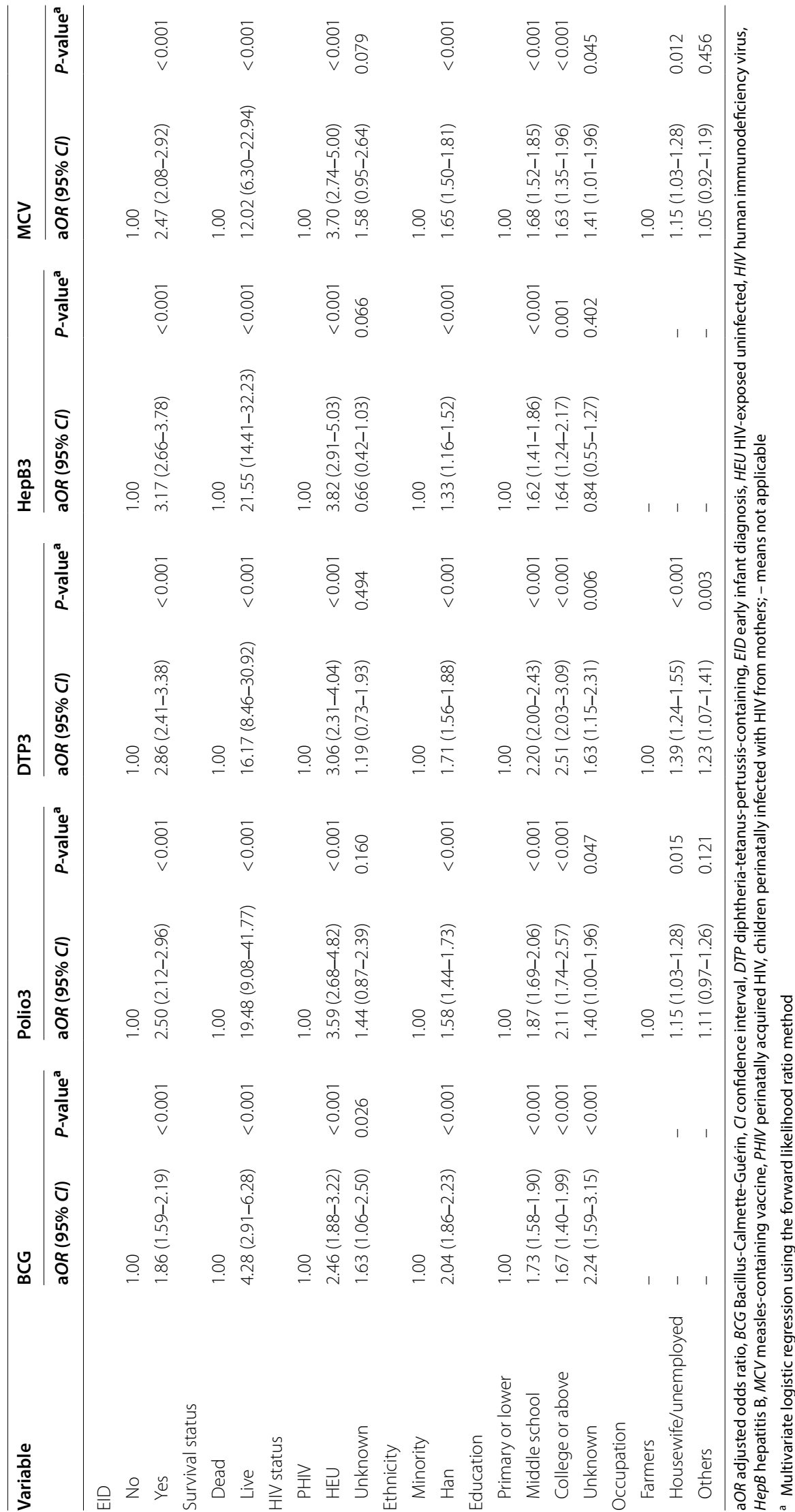


We analyzed maternal and child factors associated with insufficient vaccination coverage and found that maternal education remains a significant determinant of immunization, as previous studies have shown that the knowledge gap among uneducated women may be a barrier against immunization [2, 29]. Children of Han ethnicity were more likely to be vaccinated-approximately two times more than those from minority groups-and this may be because the minority groups had poor living conditions and lower socioeconomic status $[29,30]$. Our study showed that most children had EID for HIV infection confirmation. Such children had 1.86-3.17 times greater odds of being vaccinated than those who did not have EID. Limited HIV diagnosis services for HIVexposed children prevents the implementation of routine immunization [31].

As the diagnosis of HIV in infants is complicated by the passage of maternal HIV antibodies across the placenta, the WHO recommends EID to diagnose HIV infection among children younger than 18 months [32]. In China, HIV-exposed children should undergo EID at 42 days and 3 months of age to confirm HIV status. Meanwhile, Chinese guideline advocate that neonates of unknown HIV status should not be vaccinated with BCG until confirmed to be uninfected, which is stricter than WHO recommendations that state that neonates of unknown HIV status should be vaccinated with BCG if they have no clinical evidence suggestive of HIV infection, regardless of whether or not the mother is receiving ART [24]. We believe that the stricter Chinese recommendation may explain the low coverage of BCG vaccination and the finding that children who had EID were more likely to be vaccinated. Limited laboratory capacity in resource-constrained areas may contribute to why some children did not undergo EID [31].

In our study, HIV-related symptoms had little influence on vaccination status and had interactive effects with survival status. The likely reason for this may be that most of the deceased children died soon after birth without registered HIV-related symptoms and missed immunization. Otherwise, HIV-related symptoms could lead to HIVrelated death, and HIV-related symptoms inhibit the uptake of vaccines. Further studies should be performed to investigate the time between the appearance of HIVrelated symptoms and child death.

With the increasingly successful use of ART, most HIV-exposed children are not infected; even children with PHIV can have a normal life expectancy. Therefore, attention should be given to low vaccine coverage among children born to HIV-infected women to improve survival in this vulnerable population. Interventions should be developed with a focus on HIV-infected mothers belonging to the uneducated and minority classes. The use of mass media tools may help to improve mothers' knowledge and understanding of immunization. PMTCT services should be integrated with immunization services in the future. Particularly, more attention should be paid to EID, and the government needs to optimize recommendations for the immunization of HIV-exposed children.

Our study had some limitations. First, the data were collected from the Chinese information system for PMTCT. This may be biased by low incidence reporting due to under-detection, misclassification, and underreporting because data collection on HIV-exposed children relies on health facility reporting. Second, there have been dramatic changes from the "basic" antigens that were used to define a fully vaccinated child in the early 1980s [20]: the new combined acellular pertussis, diphtheria, tetanus, inactivated poliomyelitis, and Haemophilus influenzae type $\mathrm{b}$ conjugate vaccine has become popular recently, which may lead to misunderstanding and misreporting of the vaccination status. Third, we did not consider the factors associated with healthcare providers. Healthcare workers who are responsible for child immunization may miss opportunities for immunizing HIV-infected children. This may be because they are unaware of vaccination recommendations in this population and are therefore overly concerned about possible risks associated with the use of vaccines $[26,29,30]$ or because of limited EID services for confirming children's HIV status.

\section{Conclusions}

Chinese HIV-exposed children had low vaccination coverage. PHIV children were significantly less likely to be vaccinated than HEU children. Interventions to address this should be developed with a focus on minority children whose mothers do not have formal education. Particularly, more attention should be paid to EID to increase access to immunization. With the risk of mother-to-child transmission of HIV reduced to $5 \%$ or less, children can achieve the expected lifespan with effective treatment. More attention should be paid to the neglected immunization problem. We also strongly encourage further research on strategies to improve routine vaccination for HIV-exposed children.

\footnotetext{
Abbreviations

aOR: Adjusted odds ratio; ART: Antiretroviral therapy; BCG: Bacillus CalmetteGuérin; Cl: Confidence interval; COR: Crude odds ratio; DTP: Diphtheriatetanus-pertussis-containing; EID: Early infant diagnosis; HEU: HIV-exposed uninfected; HIV: Human immunodeficiency virus; HepB: Hepatitis B; MCV: Measles-containing vaccine; PHIV: Perinatally acquired HIV; PMTCT: Prevention of mother-to-child transmission; UTD: Up to date; WHO: World Health Organization.
} 


\section{Acknowledgements}

We thank the PMTCT staff members at the hospitals, local health departments, and county-, district-, prefecture-, and provincial-level for their valuable assistance in data collection.

\section{Authors' contributions}

RS participated in study conceptualization and design, data analysis, drafting, and editing of the manuscript. XPP conceptualized the study design and critically reviewed the manuscript for intellectual content. YPO, OW, XYW, and SLQ provided critical feedback on the manuscript. TZ and ALW conceptualized the study design, managed the development of the study, and critically reviewed the manuscript for intellectual content. All authors read and approved the final manuscript.

\section{Funding}

This work was supported by Chinese National Major Public Health Service projects and the National Natural Science Foundation grants (81773447). The funder has no role in the development or implementation of this study.

\section{Availability of data and materials}

The dataset supporting the conclusion of this article is available upon reasonable request from the corresponding author.

\section{Ethics approval and consent to participate}

It was determined by the National Health Commission of the People's

Republic of China that the collection of data from HIV-exposed cases was part of continuing public health surveillance of a notifiable infectious disease and was thus exempted from institutional review board assessment.

\section{Consent for publication}

Not applicable.

\section{Competing interests}

The authors declare that they have no competing interests.

\section{Author details}

${ }^{1}$ National Center for Women and Children's Health, Chinese Center for Disease Control and Prevention, No. 12 Dahuisi Road, Haidian District, Beijing 100081, China. ${ }^{2}$ Chinese Center for Disease Control and Prevention, 155 Changbai Road, Changping District, Beijing 102206, China. ${ }^{3}$ Capital Institute of Pediatrics, No. 2 Yabao Road, Chaoyang District, Beijing 100020, China.

Received: 11 October 2020 Accepted: 19 January 2021

Published online: 01 March 2021

\section{References}

1. World Health Organization. Immunization coverage. 2020. https://www who.int/news-room/fact-sheets/detail/immunization-coverage. Accessed 22 Sep 2020

2. Bhattacharya SD, Bhattacharyya S, Chatterjee D, Niyogi S, Chauhan N, Sudar A. Risk factors for incomplete immunization in children with HIV infection. Indian J Pediatr. 2014;81:850-5.

3. Ndirangu J, Barnighausen T, Tanser F, Tint K, Newell ML. Levels of child hood vaccination coverage and the impact of maternal HIV status on child vaccination status in rural KwaZulu-Natal, South Africa. Trop Med Int Health. 2009;14:1383-93.

4. Mast TC, Kigozi G, Wabwire-Mangen F, Sewankambo N, Serwadda D, Gray $\mathrm{R}$, et al. Immunisation coverage among children born to HIV-infected women in Rakai district, Uganda: effect of voluntary testing and counselling (VCT). AIDS Care. 2006;18:755-63.

5. Afran L, Garcia Knight M, Nduati E, Urban BC, Heyderman RS, RowlandJones SL. HIV-exposed uninfected children: a growing population with a vulnerable immune system? Clin Exp Immunol. 2014;176:11-22.

6. Evans $C$, Jones CE, Prendergast AJ. HIV-exposed, uninfected infants: new global challenges in the era of paediatric HIV elimination. Lancet Infect Dis. 2016:16:e92-107.

7. Koyanagi A, Humphrey JH, Ntozini R, Nathoo K, Moulton LH, lliff P, et al. Morbidity among human immunodeficiency virus-exposed but uninfected, human immunodeficiency virus-infected, and human immunodeficiency virus-unexposed infants in Zimbabwe before availability of highly active antiretroviral therapy. Pediatr Infect Dis J. 2011:30:45-51.

8. Slogrove AL, Goetghebuer T, Cotton MF, Singer J, Bettinger JA. Pattern of infectious morbidity in HIV-exposed uninfected infants and children. Front Immunol. 2016;7:164

9. Divala O, Michelo C, Ngwira B. Morbidity and mortality in HIV-exposed under-five children in a rural Malawi setting: a cohort study. J Int AIDS Soc. 2014:17:19696.

10. Wang A, Qiao Y, Dou L, Wang Q, Wang X, Su M, et al. Challenges of eliminating mother-to-child transmission of HIV, syphilis and hepatitis B in China: a cross-sectional survey. Lancet. 2018;392:S55.

11. Wang LH, Fang LW, Wang $Q$, Jiang $Y$, Mo $Y$, Sun DY, et al. The change trend of mother-to-child transmission rate of HIV-1 during 2005-2007 in some areas of China. Zhonghua Yu Fang Yi Xue Za Zhi. 2009:43:984-7 (in Chinese).

12. Wang $Q$, Ma N, Si H, Ma YM, Li N, Nie YG, et al. Study on the risk of mortality and associated factors among HIV-exposed children in Henan province, 2002-2014. Chin J Epidemiol. 2017;38:1629-33 (in Chinese).

13. Qiao YP, Wang AL, Wang LH. Analysis of the effectiveness of program on prevention of mother-to-child transmission of HIV in high HIV-prevalence areas from 2007 to 2010. Chin J AIDS STD. 2014;20:343-5 (in Chinese).

14. National Health Commission of the People's Republic of China. Report on the development of maternal and child health in China (2019). Chin J Women Children Health. 2019:10:1-8 (in Chinese).

15. Fang LW, Xing ZL, Wang LH, Wang Q, Zhang W, Sun DY, et al. Influencing factors on the death of infants born to HIV infected mothers. Chin J Prev Med. 2009;43:991-5 (in Chinese).

16. Frigati $L$, Archary M, Rabie H, Penazzato M, Ford N. Priorities for decreasing morbidity and mortality in children with advanced HIV disease. Clin Infect Dis. 2018:66:S147-51.

17. Moss WJ, Fisher C, Scott S, Monze M, Ryon JJ, Quinn TC, et al. HIV type 1 infection is a risk factor for mortality in hospitalized Zambian children with measles. Clin Infect Dis. 2008;46:523-7.

18. Dou L, Wang X, Wang F, Wang Q, Qiao Y, Su M, et al. Epidemic profile of maternal syphilis in China in 2013. BioMed Res Int. 2016;2016:9194805.

19. Qiao YP, Wang XY, Su M, Wang Q, Li Z, Jin X, et al. HIV early infant diagnosis test in HIV-exposed children in China, 2015-2017. Chin J Epidemiol. 2019;40:1111-5 (in Chinese).

20. World Health Organization. Harmonizing vaccination coverage measures in household surveys: A primer. 2020. https://www.google.com/ url?sa $=\mathrm{t} \&$ source $=$ web\&rct $=$ i\&url=https:/www.who.int/immunization/ monitoring_surveillance/Surveys_White_Paper_immunization_2019. pdf\%3Fua\%3D1\&ved=2ahUKEwje79jMuvrrAhVSe8AKHYQCB6AQFj ABegQIARAB\&usg=AOvVaw2dG0B_UhKTArGqq2kABfCj. Accessed 17 Sep 2020.

21. National Health Commission of the People's Republic of China. Immunization schedules and instructions for vaccines of the National Immunization Program (2016 version). Chin J Viral Dis. 2017;2017(7):81-6 (in Chinese)

22. World Health Organization. WHO vaccine-preventable diseases: monitoring system. 2020 global summary. 2020. https://apps.who.int/immun ization monitoring/globalsummary/countries?countrycriteria\%5Bcou ntry\%5D\%5B\%5D=CHN\&commit=OK. Accessed 17 Sep 2020.

23. World Health Organization. Weekly epidemiological record. 2020. https ://apps.who.int/iris/bitstream/handle/10665/260306/WER9308.pdf;jsess ionid=DB9257663C0323C35D89BA7BDFEB5C4F?sequence $=1$. Accessed 17 Sep 2020

24. World Health Organization. WHO recommendations for routine immunization—summary tables. 2020. https://www.who.int/immunization/polic y/immunization_tables/en/. Accessed 17 Sep 2020.

25. Succi RCM, Krauss MR, Harris DR, Machado DM, de Moraes-Pinto MI, Mussi-Pinhata MM, et al. Undervaccination of perinatally HIV-infected and HIV-exposed uninfected children in Latin America and the Caribbean. Pediatr Infect Dis J. 2013;32:845-50.

26. Succi RCM, Krauss MR, Harris DR, Machado DM, de Moraes-Pinto MI Mussi-Pinhata MM, et al. Immunity after childhood vaccinations in perinatally HIV-exposed children with and without HIV infection in Latin America Pediatr Infect Dis J. 2018·37:304-9. 
27. Chi P, Li X, Tam CC, Du H, Zhao G, Zhao J. Parenting mediates the impact of caregivers' distress on children's well-being in families affected by HIV/ AIDS. AIDS Behav. 2015;19:2130-9.

28. Antle BJ, Wells LM, Goldie RS, DeMatteo D, King SM. Challenges of parenting for families living with HIV/AIDS. Soc Work. 2001;46:159-69.

29. Som S, Pal M, Chakrabarty S, Bharati P. Socioeconomic impact on child immunisation in the districts of West Bengal, India. Singapore Med J. 2010;51:406-12.

30. Sensarma P, Bhandari S, Kutty VR. Barriers to immunization among children of HIV-Infected mothers in Kolkata, India. Asia Pac J Public Health. 2015;27:P1362-71.
31. Eley B. Immunization in patients with HIV infection: are practical recommendations possible? Drugs. 2008;68:1473-81.

32. World Health Organization. Updated recommendations on first-line and second-line antiretroviral regimens and post-exposure prophylaxis and recommendations on early infant diagnosis of HIV. 2018. https://www. who.int/hiv/pub/guidelines/ARV2018update/en/. Accessed 17 Sep 2020.
Ready to submit your research? Choose BMC and benefit from:

- fast, convenient online submission

- thorough peer review by experienced researchers in your field

- rapid publication on acceptance

- support for research data, including large and complex data types

- gold Open Access which fosters wider collaboration and increased citations

- maximum visibility for your research: over $100 \mathrm{M}$ website views per year

At BMC, research is always in progress.

Learn more biomedcentral.com/submissions 